\title{
Minor psychiatric disorders and their associations in family caregivers of people with mental disorders
}

\author{
Transtornos psiquiátricos menores e suas associações \\ em familiares cuidadores de pessoas com transtorno mental
}

Carlos Alberto dos Santos Treichel ${ }^{1}$

Vanda Maria da Rosa Jardim ${ }^{1}$

Luciane Prado Kantorski ${ }^{1}$

Aline dos Santos Neutzling

Michele Mandagará de Oliveira ${ }^{1}$

Valéria Cristina Christello Coimbra ${ }^{1}$

\footnotetext{
${ }^{1}$ Faculdade de Enfermagem, Universidade Federal de Pelotas. R. Gomes Carneiro 1, Porto. 96010-610 Pelotas RS Brasil.carlos-treichel@ hotmail.com
}

\begin{abstract}
This study aims to analyze the occurrence of minor psychiatric disorder and their associations in relatives of people with mental disorders. This is a cross-sectional study of 1164 relatives. For the tracking of minor psychiatric disorders the Self-Reporting Questionnaire Scale (SRQ20) was used, adopting 6/8 as cut-off point. Bivariate analyzes were conducted using Chisquared test. Trends among strata of independent variables were investigated in relation to the outcome using nonparametric linear trend test. Statistic significance was defined as p-value $<0.05$. Crude and adjusted binary logistic regressions were conducted using as a basis the hierarchical model developed through a systematic literature review. It was observed in the population a prevalence of $46.9 \%$ for minor psychiatric disorders. Higher prevalence of minor psychiatric disorders were strongly associated with the female gender, older age, first degree family ties, not having a paid work, lower education level, lower income, health problems, lower quality of life and feeling of burden. Many factors are related to the emotional and mental illness of family caregivers, demanding health services to be prepared to recognize and intervene in these situations.
\end{abstract}

Key words Minor psychiatric disorders, SRQ20, Relatives, Caregivers, Community mental health services
Resumo Este estudo tem por objetivo analisar a ocorrência de transtornos psiquiátricos menores e suas associações em familiares de pessoas com transtornos mentais. Estudo transversal realizado com 1.164 familiares. Para o rastreamento utilizou-se o Self-Reporting Questionnaire Scale (SRQ20). Análises bivariadas foram realizadas com uso do teste Qui-quadrado. Tendências entre os estratos foram investigados em relação ao desfecho por meio do teste não paramétrico de tendência linear. Significância estatística foi definida como $p$ $<0,05$. Regressões logísticas binárias brutas e ajustadas foram realizadas utilizando como base um modelo hierárquico desenvolvido através de uma revisão sistemática da literatura. Observou-se prevalência de $46,9 \%$ de transtornos psiquiátricos menores. Maior prevalência desses transtornos esteve fortemente associada ao sexo feminino, idade avançada, laços familiares de primeiro grau, não possuir trabalho remunerado, nivel de educação mais baixo, menor renda, problemas de saúde, baixa qualidade de vida e sentimento de sobrecarga. Muitos fatores estão associados à doença emocional e mental dos cuidadores familiares, exigindo que serviços de saúde estejam preparados para reconhecer e intervir nessas situações.

Palavras-chave Transtornos psiquiátricos menores, SRQ20, Familiares, Cuidadores, Serviços comunitários de saúde mental 


\section{Introduction}

With the advent of psychiatric deinstitutionalization processes experienced in Brazil in recent decades, several changes with respect to the care of people with mental disorders have been tensioned. Care actions previously restricted to hospital are now designed for the community, allowing the individual, previously segregated and excluded from social contact, to be reinserted in society ${ }^{1}$.

With care actions designed to the community in which the individual is located, the way of perceiving the family, without doubt, is one of the major changes in this new scene. The family during the history of psychiatry was seen as an accomplice of the social isolation of the individual or even the cause of the illness, is now seen as one of the protagonists of care ${ }^{2}$.

The rescue of the family as part of the care process proves itself as a valuable strategy for caring community basis. Since family members are, often, the bridge between users and the society. And care is only possible when the means and resources available to care for the patient are considered, including the family $y^{3,4}$.

However, it should be considered that the family interferes in the health-disease process of its members, organizing, disorganizing and reorganizing itself continuously. Therefore the diagnosis of a psychiatric disorder can have a major impact on the family, which now has to live with the doubts that come with a mental disease ${ }^{4}$. It's also noteworthy that in this situation, a new role is assigned to some relatives, the caregiver role.

In the role of caregivers, family members start to experience multiple and challenging tasks for which they often are not prepared. And although they have positive feelings about their diseased relative, they sometimes cannot deal well with their emotions facing the reality of doubts and uncertainties ${ }^{4}$.

A previous study ${ }^{5}$ found that the tasks arising from the caregiver role as well as the changes that occur in their social and professional life, end up burdening the family which can often experience feelings of anxiety and depression, suffering negative consequences within the family and in social life and work environment.

Feelings of anxiety and depression involved in these situations can be classified as minor psychiatric disorders (MPD), which designate a scenario where the individual do not meet all the criteria of mental illness according to the International Classification of Diseases (ICD-10).
Expanding this understanding, it can be said that the MPD refer to somatic problems involving non-psychotic psychiatric symptoms, including insomnia, fatigue, irritability, depression and anxiety feelings, forgetfulness and difficulty concentrating ${ }^{6}$.

Given this reality and the need to explore the subject, this study aimed to analyze the occurrence of minor psychiatric disorders in the relatives of community-based mental health services' users in southern Brazil. Identifying associated factors, so new perspectives can be tensioned in order to solving this problem.

\section{Methodology}

This cross-sectional study, clipping of a community-based mental health service evaluation research held in 2011 in southern Brazil (CAPSUL II).

The population in the study consists of 1164 relatives of people with mental disorders, submitted to the application of a pre-structured form including variables about sociodemographic data, health, aspects related to the care, burden, quality of life, and for the tracking of minor psychiatric disorders, the Self-Reporting Questionnaire Scale (SRQ20) was used.

The SRQ20 scale was developed by Harding et al. ${ }^{7}$ and validated in Brazil by Mari and Williams. ${ }^{8}$. The scale consists of twenty questions with yes/no answers and according to Harding et al. ${ }^{7}$, the cut-off point, number of positive issues that determine the presence of a minor psychiatric disorder, has a considerable variation from $5 / 6$ to $10 / 11$, depending on the cultural context in which it is applied, including location and temporal contexts. This study used as model the Brazilian validation, in which Mari and Williams ${ }^{8}$ found a sensitivity and specificity of $83 \%$ and $80 \%$ respectively when used as cut-off point $6 / 8$, being the first number the cut-off point for men and the second for women.

The study protocol was approved under technical opinion No. 176/2011, by the Ethics Committee of the Faculty of Nursing of the Federal University of Pelotas following the Standards and Guidelines for the Regulation of Research Involving Human Beings - CNS Resolution 196/96, the aspects of this study also conform to the CNS Resolution 466/2012. Ethical principles were assured by: informed consent; guarantee of right not to participate in the research and anonymity.

Data collection occurred in 40 Centers for Psychosocial Care (CAPS) - community-based 
psychiatric services - distributed in the three states of southern Brazil and was held for 40 independent interviewers previously selected and trained.

Quality control was carried out in the encoding of data collection instruments; the review conducted by supervisors to receive the questionnaires; replication 5\% of interviews.

The data went through double entry in the software EPI-INFO, differences between information were compared and evaluated. The same database was used for necessary corrections.

Data analysis was performed using the software STATA 11 (Stata Corp., College Station, USA) and IBM SPSS Statistics.

Bivariate analyzes were conducted using the Chi-squared test, adopting as significant a p-value $<0.05$. Trends among strata of independent variables were investigated in relation to the outcome using nonparametric linear trend test, using as significant values of nptrend $<0.05$.

Crude and adjusted binary logistic regressions were conducted. For the adjusted analysis the hierarchical model, arranged in Figure 1 and prepared by literature review, was used. Same level variables were adjusted among each other and for the second level were kept in the analysis those who remained associated with the outcome ( $\mathrm{p}$-value $<0.2$ ), in addition to those of the same level. For inclusion of variables in the adjusted model was used as criterion a $\mathrm{p}$-value $<0.2$, however, the statistical significance remained as a p-value $<0.05$.

\section{Results}

In the population it was observed a prevalence of $46.9 \%$ of minor psychiatric disorders. Table 1 provides the prevalence of minor psychiatric disorders according to the profile of the relatives included in the study.

Similarly, Table 2 expresses the prevalence of MPD according to the health conditions of family members who made up the sample. It is possible to observe the variation in prevalence due to whether or not having a health problem, behavior in relation to alcohol and tobacco, number of medical appointments in the last 6 months and self-assessment of quality of life.

The relationship between the outcome and the aspects of care included in the study were also explored. The prevalence of minor psychiatric disorders in relation to variables that expressed these characteristics is arranged in Table 3.

Table 4 refers to the odds ratio found in the crude and adjusted analyzes for each variable, as well as confidence intervals and p-values to compare statistical significance.

Through the data presented it is possible to observe that some variables lost statistical significance in the adjusted analysis, they are: medical appointments in the last 6 months, alcohol intake and smoking. There were also variables that were removed from the model for not remaining associated with the outcome (presenting a p-value $<$ 0.2 ). They are: marital status and sharing of care.

The adjusted analysis suggests that females are $70 \%$ more likely to have a positive outcome for minor psychiatric disorders. Similarly, in-

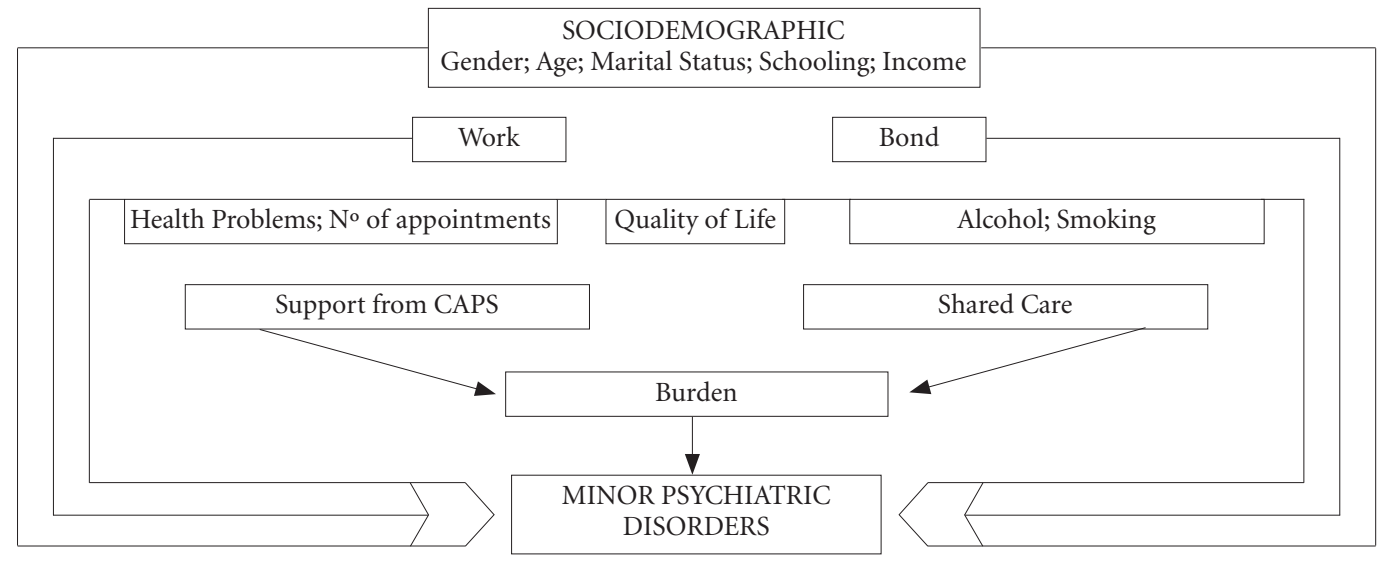

Figure 1. Theoretical Hierarchized Model. 
Table 1. Profile of relatives of CAPS users included in the study according to the prevalence of minor psychiatric disorders.

\begin{tabular}{|c|c|c|c|}
\hline Characteristics of relatives & $\begin{array}{c}\text { Negative Screening } \\
\text { for MPD }\end{array}$ & $\begin{array}{c}\text { Positive Screening } \\
\text { for MPD }\end{array}$ & P-value \\
\hline \multicolumn{4}{|l|}{ Gender } \\
\hline Masculine & $62 \%(238)$ & $38 \%(380)$ & \multirow[t]{2}{*}{$<0,001$} \\
\hline Feminine & $49 \%(146)$ & $51 \%(400)$ & \\
\hline \multicolumn{4}{|l|}{ Relationship with patient } \\
\hline Others & $69 \%(85)$ & $31 \%(38)$ & \multirow[t]{5}{*}{$<0,001$} \\
\hline Sibling & $59 \%(112)$ & $41 \%(79)$ & \\
\hline Child & $52 \%(90)$ & $48 \%(83)$ & \\
\hline Spouse & $52 \%(148)$ & $48 \%(137)$ & \\
\hline Parent & $47 \%(183)$ & $53 \%(209)$ & \\
\hline \multicolumn{4}{|l|}{ Marital Status } \\
\hline Single & $59 \%(116)$ & $41 \%(81)$ & \multirow[t]{3}{*}{0,023} \\
\hline Married & $54 \%(381)$ & $46 \%(326)$ & \\
\hline Separated/Divorced/Widowed & $46 \%(119)$ & $54 \%(138)$ & \\
\hline \multicolumn{4}{|l|}{ Age } \\
\hline 14 to 25 & $63 \%(62)$ & $37 \%(37)$ & \multirow[t]{4}{*}{0,006} \\
\hline 26 to 45 & $58 \%(181)$ & $42 \%(133)$ & \\
\hline 46 to 65 & $48 \%(266)$ & $52 \%(288)$ & \\
\hline $66+$ & $55 \%(108)$ & $45 \%(87)$ & \\
\hline \multicolumn{4}{|l|}{ Education } \\
\hline High school or Higher education & 67 (195) & $33 \%(94)$ & \multirow[t]{3}{*}{$<0,001$} \\
\hline Complete elementary school & $49 \%(103)$ & $51 \%(109)$ & \\
\hline Incomplete elementary school & $48 \%(320)$ & $52 \%(341)$ & \\
\hline \multicolumn{4}{|l|}{ Paid work } \\
\hline Yes & $59 \%(285)$ & $41 \%(196)$ & \multirow[t]{2}{*}{$<0,001$} \\
\hline No & $49 \%(333)$ & $51 \%(350)$ & \\
\hline \multicolumn{4}{|l|}{ Family monthly income ${ }^{\star}$} \\
\hline $5+$ minimum wages & $69 \%(91)$ & $31 \%(40)$ & \multirow[t]{6}{*}{$<0,001$} \\
\hline From 3 to 4 minimum wages & $54 \%(69)$ & $46 \%(59)$ & \\
\hline From 2 to 3 minimum wages & $52 \%(176)$ & $48 \%(123)$ & \\
\hline From 1 to 2 minimum wages & $48 \%(176)$ & $52 \%(190)$ & \\
\hline Up to 1 minimum wage & $47 \%(87)$ & $53 \%(98)$ & \\
\hline Did not answer & $63 \%(61)$ & $37 \%(36)$ & \\
\hline
\end{tabular}

Source: CAPSUL, 2011. * National minimum wage in the time of data collection: R\$ 545,00.

dividuals with closer ties to the user were more likely to present this outcome. This idea is reinforced by the linear trend test that identified a significant value of $\mathrm{p} \leq 0.001$.

Individuals aged from 46 to 65 years are the ones more likely to develop minor psychiatric disorders, the results indicate that the chance is $62 \%$ higher in this group. Even though in the subjects aged 66 or more the chances of developing minor psychiatric disorder decrease, the linear trend test points a significance of $p=0.04$ for the existence of a trend in which the higher the age the higher the prevalence of minor psychiat- ric disorders. The same applies to level of education ( $p \leq 0.001)$. It is possible to observe that individuals with lower education level are about 2 times more likely to develop a minor psychiatric disorder that individuals with higher education.

Having a paid work proved to be a protective factor against the outcome, as among individuals who reported not having a paid job the chances of developing a minor psychiatric disorder were $31 \%$ higher.

Family income showed a linear trend in relation to the outcome $(\mathrm{p}=0.01)$ showing that the lower the income the higher the chances of pre- 
Table 2. Health conditions of relatives of CAPS users included in the study according to the prevalence of minor psychiatric disorders.

\begin{tabular}{lccc}
\hline \multicolumn{1}{c}{ Health conditions } & $\begin{array}{c}\text { Negative screening } \\
\text { for MPD }\end{array}$ & $\begin{array}{c}\text { Positive screening } \\
\text { for MPD }\end{array}$ & P-value \\
\hline Health problem & $68 \%(373)$ & $32 \%(179)$ & $<0,001$ \\
No & $40 \%(245)$ & $60 \%(367)$ & \\
Yes & & & \\
Medical appointments in the last 6 months & $60 \%(230)$ & $40 \%(154)$ & $<0,001$ \\
None & $54 \%(315)$ & $46 \%(266)$ & \\
1 to 3 & $37 \%(67)$ & $63 \%(112)$ & \\
4 or more & $30 \%(6)$ & $70 \%(14)$ & \\
Did not answer & & & \\
Alcohol intake & $51 \%(471)$ & $49 \%(463)$ & \\
Never & $65 \%(71)$ & $35 \%(38)$ & \\
Once a month or less & $59 \%(40)$ & $41 \%(28)$ & \\
2 to 4 times a month & $67 \%(34)$ & $33 \%(17)$ & \\
More than twice a week & & & \\
Smoking & $55 \%(508)$ & $45 \%(421)$ & \\
No & $47 \%(109)$ & $53 \%(125)$ & \\
Yes & & $34 \%(142)$ & \\
Quality of life & $66 \%(273)$ & $42 \%(120)$ & \\
Excellent & $58 \%(167)$ & $75 \%(155)$ & \\
Good & $49 \%(121)$ & & \\
Regular & $25 \%(53)$ & & \\
Poor & & &
\end{tabular}

Source: CAPSUL, 2011.

Table 3. Aspects of care among relatives of CAPS users included in the study according to the prevalence of minor psychiatric disorders.

\begin{tabular}{lccc}
\hline \multicolumn{1}{c}{ Aspects of Care } & $\begin{array}{c}\text { Negative Screening for } \\
\text { MPD }\end{array}$ & $\begin{array}{c}\text { Positive Screening } \\
\text { for MPD }\end{array}$ & P-value \\
\hline Shared Care & & & \\
$\quad$ Does not share & $51 \%(402)$ & $49 \%(386)$ & 0,028 \\
$\quad$ Shares with 1 other & $57 \%(90)$ & $43 \%(69)$ & \\
$\quad$ Shares with 2 others & $52 \%(70)$ & $48 \%(64)$ & \\
Shares with 3 others & $67 \%(56)$ & $33 \%(27)$ & \\
Feeling of Burden & & & \\
Does not feel burdened & $69 \%(378)$ & $31 \%(173)$ & $<0,001$ \\
Feels somewhat burdened & $52 \%(51)$ & $54 \%(113)$ & \\
Sometimes feels burdened & $46 \%(96)$ & $70 \%(211)$ & \\
Feels very burdened & $30 \%(91)$ & & \\
Support from CAPS when burdened & & $32 \%(177)$ & $<0,001$ \\
Does not feel burdened & $68 \%(375)$ & $60 \%(193)$ & \\
Receives support & $40 \%(129)$ & $62 \%(168)$ & \\
Does not receive support & $38 \%(104)$ & $44 \%(8)$ & \\
Did not answer & $56 \%(10)$ & & \\
\hline
\end{tabular}

Source: CAPSUL, 2011. 
senting a disorder. It is observed that compared to individuals whose families earned more than five minimum wages, individuals who had lower family income had chances $54-70 \%$ higher to present minor psychiatric disorders.

Having a health problem was also associated with higher chances of presenting minor psychiatric disorders. Chances among individuals with health problems were 2.63 times greater than among healthy individuals. Similarly, the variable referring to the number of medical appointments in the past six months indicates a greater chance of presenting the outcome on those individuals with most appointments. However, in the adjusted analysis this variable lost statistical significance, and the confidence intervals suggest that, considering the event in the general population, the variable can be shown both as a protective and risk factor. The same applies to alcohol intake and smoking, that also lost statistical significance.

Quality of life had an association to outcome, confirmed by linear trend test $(p \leq 0.001)$, in which the worse the evaluation of quality of life the greater the chance of presenting minor psychiatric disorders. It is observed that individuals who have the worst rating of quality of life are 5.16 times more likely to have a positive screening for minor psychiatric disorders.

The manifestation of feelings of burden also tended towards the outcome. According to the data of Table 4, the greater the feeling of burden, the greater is the chance of developing a minor psychi-

Table 4. Brute and adjusted analyzes of the effect of the independent variables on the positive outcome of minor psychiatric disorders.

\begin{tabular}{|c|c|c|c|c|}
\hline \multirow{2}{*}{ Variables } & \multicolumn{2}{|c|}{ Brute Analysis } & \multicolumn{2}{|c|}{ Adjusted Analysis } \\
\hline & OR CI 95\% & P-value & OR CI 95\% & P-value \\
\hline \multicolumn{5}{|l|}{ Gender } \\
\hline Male & 1 & 0,0000 & 1 & 0,0000 \\
\hline Female & $1,71(1,34 ; 2,20)$ & & $1,70(1,31 ; 2,21)$ & \\
\hline \multicolumn{5}{|l|}{ Bond } \\
\hline Other & 1 & $<0,001^{\star}$ & 1 & 0,0002 \\
\hline Sibling & $1,58(0,98 ; 2,54)$ & 0,0002 & $1,51(0,92 ; 2,49)$ & \\
\hline Spouse & $2,07(1,32 ; 3,23)$ & & $2,36(1,46 ; 3,81)$ & \\
\hline Child & $2,06(1,27 ; 3,35)$ & & $2,56(1,53 ; 4,26)$ & \\
\hline Parents & $2,55(1,66 ; 3,93)$ & & $2,37(1,51 ; 3,72)$ & \\
\hline \multicolumn{5}{|l|}{ Age } \\
\hline 14 to 25 & 1 & 0,0061 & 1 & 0,0318 \\
\hline 26 to 45 & $1,23(0,77 ; 1,96)$ & $0,04^{*}$ & $1,21(0,74 ; 1,96)$ & \\
\hline 46 to 65 & $1,81(1,17 ; 2,82)$ & & $1,62(1,02 ; 2,58)$ & \\
\hline $66+$ & $1,34(0,82 ; 2,21)$ & & $1,12(0,66 ; 1,91)$ & \\
\hline \multicolumn{5}{|l|}{ Education } \\
\hline High School or Superior Education & 1 & 0,0000 & 1 & 0,0000 \\
\hline Complete elementary school & $2,19(1,65 ; 2,95)$ & $<0,001^{\star}$ & $1,99(1,44 ; 2,75)$ & \\
\hline Incomplete elementary school & $2,21(1,52 ; 3,19)$ & & $2,03(1,39 ; 2 ; 97)$ & \\
\hline \multicolumn{5}{|l|}{ Paid work } \\
\hline Yes & 1 & 0,0004 & 1 & 0,0448 \\
\hline No & $1,53(1,20 ; 1,93)$ & & $1,31(1,0 ; 1,72)$ & \\
\hline \multicolumn{5}{|l|}{ Income } \\
\hline $5+$ minimum wages & 1 & 0,0001 & 1 & 0,0770 \\
\hline From 3 to 4 minimum wages & $1,94(1,17 ; 3,23)$ & $0,01^{\star}$ & $1,54(0,91 ; 2,62)$ & \\
\hline From 2 to 3 minimum wages & $2,09(1,34 ; 3,25)$ & & $1,68(1,05 ; 2,67)$ & \\
\hline From 1 to 2 minimum wages & $2,46(1,60 ; 3,75)$ & & $1,70(1,08 ; 2,68)$ & \\
\hline Up to 1 minimum wage & $2,56(1,60 ; 4,10)$ & & $1,68(1,01 ; 2,78)$ & \\
\hline Did not answer & $1,34(0,77 ; 2,33)$ & & $1,03(0,57 ; 1,84)$ & \\
\hline \multicolumn{5}{|l|}{ Health Problems } \\
\hline No & 1 & 0,0000 & 1 & 0,0000 \\
\hline Yes & $3,12(2,45 ; 3,97)$ & & $2,63(1,95 ; 3 ; 55)$ & \\
\hline
\end{tabular}


Table 4. continuation

\begin{tabular}{|c|c|c|c|c|}
\hline \multirow{2}{*}{ Variables } & \multicolumn{2}{|c|}{ Brute Analysis } & \multicolumn{2}{|c|}{ Adjusted Analysis } \\
\hline & OR CI 95\% & P-value & OR CI 95\% & P-value \\
\hline \multicolumn{5}{|c|}{ Medical appointments in the last 6 months } \\
\hline None & 1 & 0,0000 & 1 & 0,0696 \\
\hline 1 to 3 & $1,26(0,97 ; 1,63)$ & & $0,94(0,69 ; 1,28)$ & \\
\hline 4 or more & $2,49(1,73 ; 3,59)$ & & $1,44(0,93 ; 2,21)$ & \\
\hline Did not answer & $3,48(1,31 ; 9,26)$ & & $2,51(0,80 ; 7,90)$ & \\
\hline \multicolumn{5}{|l|}{ Alcohol intake } \\
\hline Never & 1 & 0,0030 & 1 & 0,1979 \\
\hline Once a month or less & $0,54(0,36 ; 0,82)$ & & $0,71(0,44 ; 1,14)$ & \\
\hline 2 to 4 times a month & $0,71(0,43 ; 1,17)$ & & $1,23(0,68 ; 2,20)$ & \\
\hline More than twice a week & $0,51(0,28 ; 0,92)$ & & $0,60(0,30 ; 1,22)$ & \\
\hline \multicolumn{5}{|l|}{ Smoking } \\
\hline No & 1 & 0,0266 & 1 & 0,0683 \\
\hline Yes & $1,38(1,04 ; 1,84)$ & & $1,36(0,97 ; 1,91)$ & \\
\hline \multicolumn{5}{|l|}{ Quality of life } \\
\hline Excellent & 1 & 0,0000 & 1 & 0,0000 \\
\hline Good & $1,38(1,01 ; 1,88)$ & $<0,001^{\star}$ & $1,77(1,25 ; 2,50)$ & \\
\hline Regular & $2,03(1,47 ; 2,80)$ & & $2,49(1,73 ; 3,58)$ & \\
\hline Poor & $5,62(3,87 ; 8,15)$ & & $5,16(3,45 ; 7,72)$ & \\
\hline \multicolumn{5}{|l|}{ Feeling of Burden } \\
\hline Does not feel burdened & 1 & 0,0000 & 1 & 0,0045 \\
\hline Feels somewhat burdened & $2,05(1,33 ; 3,17)$ & $<0,001^{\star}$ & $2,89(0,88 ; 9,44)$ & \\
\hline Sometimes feels burdened & $2,57(1,85 ; 3,56)$ & & $3,16(1,00 ; 10,00)$ & \\
\hline Feels very burdened & $5,06(3,73 ; 6,87)$ & & $5,16(1,63 ; 16,35)$ & \\
\hline \multicolumn{5}{|c|}{ Support from CAPS when burdened } \\
\hline Does not feel burdened & 1 & 0,000 & 1 & 0,0000 \\
\hline Receives support & $3,17(2,38 ; 4,21)$ & & $2,65(1,92 ; 3,65)$ & \\
\hline Does not receive support & $3,42(2,52 ; 4,63)$ & & $2,89(2,06 ; 4,07)$ & \\
\hline Did not answer & $1,69(0,65 ; 4,36)$ & & $1,93(0,64 ; 5,82)$ & \\
\hline
\end{tabular}

Source: CAPSUL, 2011. ${ }^{*}$ p-value for linear trend test.

atric disorder. Among individuals who felt somewhat burdened, the odds were 2.89 times higher, while in individuals who sometimes felt overloaded with care were 3.16 times higher and those who felt very burdened were 5.16 times higher.

Caregiver's relatives that reported burden were asked about CAPS Support. So, the comparison was drawn between who did not report burden and those who received support; those who did not receive support; or those who did not answer. In this sense, relatives, who did not receive support when they felt burdened, demonstrated 2.89 times higher probability for MPD compared to those who did not report burden.

\section{Discussion}

The screening for psychiatric disorders in the population in study was positive in $46.9 \%$ of cases. This prevalence is close to that found in other studies that also applied SRQ20 scale to caregivers in mental health. Studies such as those of Quadros et al. ${ }^{9}$ and Tomasi et al. ${ }^{10}$ found a prevalence of $49 \%$ and $41 \%$ respectively.

The prevalence of minor psychiatric disorders in this population can be compared even with those found in other populations of caregivers who do not deal with mental health. Caregivers of patients who have been affected by stroke, for example, had a prevalence of $44.3 \%$ in a study 
conducted by Morais et al. ${ }^{11}$. Similarly, Silva et al. ${ }^{12}$ found a prevalence of $46.55 \%$ in caregivers of elderly with dementia.

These findings corroborate the idea that family caregivers are a risk group for development of these disorders. Since based on population-based studies conducted earlier in this country ${ }^{13-15}$, the prevalence of minor psychiatric disorders among caregivers was higher when compared to the general population.

Although Gonçalves and Sena ${ }^{16}$ point to the female gender as the one who finds it easier to deal with suffering, as well as Quadros et al. ${ }^{9}$, this study found a higher prevalence of minor psychiatric disorders among women, with differences statistically significant between the averages presented ( $\mathrm{p} \leq 0.001)$. The adjusted analysis measured that females were $70 \%$ more likely to have these disorders.

Following studies of Tunde-Ayinmode ${ }^{17}$, Quadros et al. ${ }^{9}$ and Silva et al. ${ }^{12}$, higher prevalence of minor psychiatric disorders were also found in the strata covering older individuals, with a linear trend (0.04) on the chances of presenting a positive outcome according to the age of the individual.

Studies of Tunde-Ayinmode ${ }^{17}$, Quadros et al. ${ }^{9}$ and Silva et al. ${ }^{12}$ also found higher prevalence of these disorders in individuals with lower education level, suggesting that education may be a protective factor. Thus, this study showed a linear trend $(<0.001)$ as to the chances of presenting positive outcome for minor psychiatric disorders due to a lower level of education. According to the adjusted analysis conducted in this study, individuals with incomplete primary education were 2.03 times more likely to have these disorders in relation to family members who had secondary or higher education.

Marital status seemed to establish a different relationship with the outcomes between studies tracked for comparison. In the study of Silva et al. ${ }^{12}$ individuals with a partner had a higher prevalence of the outcome studied, whereas the study by Quadros et al. ${ }^{9}$ highest prevalence rates were found among subjects without companions. The results of this study are closer to those found by Silva et al. ${ }^{12}$ meaning that subjects in a relationship manifest higher prevalence of minor psychiatric disorders. However, this study also has a corresponding layer to individuals who have lost their partners or divorced them, whose subjects had higher prevalence of minor psychiatric disorders. The $\mathrm{p}$-value for the difference of the average presented for marital status was $p=0.023$, but when inserted in the model, this variable lost statistical significance.

Considering that the loss or separation of a spouse can be a stressor, it is assumed that the evaluation of these factors is relevant within the studied outcome. In this sense, the study of Quadros et al. ${ }^{9}$ conducted this assessment and found a higher prevalence of minor psychiatric disorders among individuals who have been through such events. It is worth noting that in the same study, the prevalence of these disorders increased as increased the number of stressful events experimented by the individuals. Thus, it is considered as a limiting factor that this study did not rely on this information, suggesting their inclusion in future studies.

The increasing prevalence of minor psychiatric disorders related to the closeness of the familial bond evidenced in this study, follows the results found by Quadros et al. ${ }^{9}$ and Silva et al. ${ }^{12}$. It can be observed that in relation to bonds other than first degree, parents, children and spouses showed 2.36 to 2.56 times more chance to have a minor psychiatric disorder. There was a linear trend for this factor due to the proximity of the bond ( $\mathrm{p} \leq 0.001)$.

Being constantly exposed to the caregiver function also appeared to contribute to a higher prevalence of minor psychiatric disorders. This suggestion comes from the lower rates of these disorders in individuals who had paid work both in this study and those of Quadros et al. ${ }^{9}$ and Silva et al. ${ }^{12}$. In the adjusted analysis, individuals who did not have paid work were $31 \%$ more likely to have minor psychiatric disorders.

Other studies conducted with family caregivers $^{11,12,18,19}$ have evaluated the influence of time devoted to the care, as well as the time of diagnosis and time as a caregiver in the care implications. In general, their results show greater impairment in individuals who care for longer and those who dedicated more or all of their time to these activities, suggesting that the impact of caring are also related to the chronification of care. It is considered as a limiting factor for this study that it did not rely on this information, suggesting the inclusion of these factors in future studies.

As in studies of Quadros et al. ${ }^{9}$ and Silva et al. ${ }^{12}$, the higher the income presented by the individuals, the lower the prevalence of minor psychiatric disorders, with a linear trend in this relationship ( $p=0.01)$. It is suggested that income would be a protective factor for this outcome, since in comparison to individuals who were allocated in families earning 5 or more minimum 
wages per month, the relatives whose families earned up to 4 minimum wages had $54 \%$ to $70 \%$ more chance to have these disorders.

Corroborating the idea that health problems could contribute to the presentation of minor psychiatric disorders, the results of this study indicated that the prevalence of these disorders was higher among individuals with health problems. The prevalence in these individuals was of $60 \%$, while in the relatives who reported being healthy was of $32 \%$. It stands out in the adjusted analysis that the chances of presenting minor psychiatric disorders were 2.63 times higher among subjects who reported having health problems.

Quadros et al. ${ }^{9}$ found similar results. In their study, the prevalence of minor psychiatric disorders in individuals who had health problems was $61.7 \%$, while in healthy individuals it was 43.9\%. Other researches that have studied the implications of care in caregivers ${ }^{11,12,18}$ also found associations between health problems and the outcome.

It was also found that individuals who had four or more medical appointments in the last 6 months had a higher prevalence of minor psychiatric disorders. The prevalence for these individuals was $63 \%$ while for individuals who did not consult with a doctor any time was $32 \%$, with statistical difference between those averages ( $\mathrm{p}=$ $<0.001)$. This reality within the adjusted analysis reflected in chances $44 \%$ higher of presenting disorders in family members who had consulted four or more times compared to those who did not have any appointment in the same period.

However, when the variable was inserted in the model, it has shown any statistical significance. Given the confidence interval (CI: 0.93; 2.21 ), it can be a chance association.

As in other study ${ }^{20}$, lower quality of life evaluation was associate to emotional illness. A higher prevalence of minor psychiatric disorders was observed in individuals who worse evaluated their quality of life. The prevalence of the MPD increased when the strata assessment was worse. While in individuals who rated their quality of life as excellent the prevalence was $34 \%$, in subjects who rated their quality of life as poor, the prevalence reached $75 \%$. Similarly, the adjusted analysis showed that individuals who rated the worst their quality of life, were 5.16 times more likely to have disorders than those who rated their quality of life as excellent.

Other studies, such as Amendola et al. ${ }^{21}$ and Amendola et al. ${ }^{22}$, have addressed the quality of life of family caregivers and found a number of factors that influence a worse assessment of quality of life. In the same sense, considering that this it is a cross-sectional study, it is necessary the reflection on the established causal relationship between the minor psychiatric disorders and quality of life. A poorer quality of life can contribute to the development of these disorders, as well as a worse assessment can also result from the presence of a minor psychiatric disorder. In this equation, it should also be considered the subjectivity attributed to the concept of quality of life for each individual.

Although there were statistically significant differences in the average prevalence of minor psychiatric disorders among individuals who used alcohol or tobacco, in the adjusted analysis these variables lost statistical significance. In the study by Silva et al. ${ }^{12}$, a higher prevalence of minor psychiatric disorders was found among family caregivers who used these substances. In this study, though, while smoking followed the same results above mentioned, the use of alcohol was associated with a lower prevalence of these disorders.

Despite, Quadros et al. ${ }^{9}$ found out a lower prevalence of minor psychiatric disorders in relatives who shared helping activities with others, in this study, the sharing care variable lost statistical significance when inserted in the model.

Although this study points that burden is not explanatory enough to determine the positive outcome of minor psychiatric disorders, its results suggest that this is an aggravating factor that deserves mention. It can be observed that in the studied sample, as the feeling of burden increased so did the prevalence of these disorders.

While among individuals who did not feel burdened the prevalence was 31\%, for individuals who reported feeling very burdened it was $70 \%$. It can also be noted that according to the adjusted analysis, the chances of presenting minor psychiatric disorders among very much burdened relatives were 5.16 times higher than those who did not manifest this feeling. Similarly, when conducting an adjusted analysis, Quadros et al. ${ }^{9}$ found burdened individuals were $49 \%$ more likely to present these disorders when compared to non burdened relatives.

In previous studies, when working with the burden of family caregivers in mental health, other authors ${ }^{10,23}$ pointed to the need of developing interventions within the community mental health services, in order to give support to these subjects. In this sense, the results of this study corroborate this view by indicating that individ- 
uals who reported receiving CAPS support at the moment of burden showed lower prevalence and were less likely to develop minor psychiatric disorders than those who did not receive such help.

\section{Conclusion}

Considering studies conducted in the general population and the results of this study, it is concluded that there is a higher prevalence of minor psychiatric disorders among family caregivers, suggesting that the population that needs attention.

Higher prevalence of minor psychiatric disorders were strongly associated with female gender, older age, first degree family ties, not having a paid work, lower education level, lower income, health problems, worse evaluation of quality of life and feeling of burden. Therefore, it is concluded that several factors are related to the emotional and mental illness in family caregivers, demanding that health services are prepared to recognize and intervene in these situations through supportive measures and for carrying out the necessary referrals within the network services available in the health system.

For this study, some limitations were considered, such as not having information about the amount of time spend in the caregiver role, the amount of time spent on care, characteristics about the user in care and stressors. The inclusion of these features is suggested for future studies.

\section{Collaborations}

CAS Treichel, VMR Jardim and LP Kantorski worked on the design, conception, analysis and interpretation of data and writing of the manuscript. AS Neutzling worked in data analysis. MM Oliveira and VCC Coimbra worked on critic review. 


\section{References}

1. Jorge R, Chaves AC. The Experience of Caregiving Inventory for first-episode psychosis caregivers: validation of the Brazilian version. Schizophr Res 2012; 138(2):274-279.

2. Camatta MW, Schneider JF. The work of the staff of a Center for Psychosocial Care in the family perspective. Rev. esc. enferm. USP. 2009; 43(2):393-400.

3. Brasil. Ministério da Saúde (MS). Mental health in SUS: the centers for psychosocial care/Ministry of Health, Department of Health Care, Department of Programmatic Strategic Actions. Brasília: MS; 2004.

4. Oliveira RMP, Loyola CM. Psychiatric Patient family: a conspicuous unknown portrait. Acta Scientiarum. Health Sciences 2004; 26(1):213-222.

5. Bandeira M, Calzavara MCP, Castro I. Burden of care in relatives of psychiatric patients: Validity study of the Family Burden Interview Scale. J. bras. Psiquiatr. 2008; 57(2):98-104.

6. Tavares JP, Beck CLC, Magnago TSBS, Greco PBT, Prestes FC, Silva RM. Scientific production on the minor psychological distress from the Self-report questionnaire. REUFSM 2011; 1(1):113-123.

7. Harding TW, De Arango MV, Baltazar J, Climent CE, Ibrahim HHA, Ladrido-Ignacio L, Murthy RS, Wig NN. Mental disorders in primary health care: a study of their frequency and diagnosis in four developing countries. Psychol Med 1980; 10:231-241.

8. Mari JJ, Williams P. A validity study of a psychiatric screening questionnaire (SRQ-20) in primary care in the city of Sao Paulo. BJP 1986; 148:23-26.

9. Quadros LC, Gigante DP, Kantorski LP, Jardim VMR. Minor psychiatric disorders in family caregivers of users of Psychosocial Care Centers in southern Brazil. Cad Saude Publica 2012; 28(1):95-103.

10. Tomasi E, Rodrigues JO, Feijó GP, Facchini LA, Piccini RX, Thumé E, Silva RA, Gonçalves H. Family burden in relatives of psychiatric patients in Psychosocial Attention Centers. Saúde Debate 2010; 34(84):159-167.

11. Morais HCC, Soares AMG, Oliveira ARS, Carvalho CML, Silva MJ, Araujo TL. Burden and modifications in life from the perspective of caregivers for patients after stroke. Rev Lat Am-enfermagem 2012; 20(5):944953.

12. Silva CF, Passos VMA, Barreto SM. Frequency and impact of the burden on family caregivers of elderly with dementia. Rev. bras. geriatr. Gerontol. 2012; 15(4):707731.

13. Volcan SMA, Sousa PLR, Mari JJ, Horta BL. Relationship between spiritual well-being and minor psychiatric disorders: a cross-sectional study. Rev. Saúde Públ. 2003; 37(4):440-445.
14. Maragno L, Goldbaum M, Gianini RJ, Novaes HMD, Cesar CLG. Prevalence of common mental disorders in a population covered by the Family Health Program (QUALIS) in São Paulo, Brazil. Cad Saude Publica 2006; 22(8):1639-1648.

15. Gonçalves DM, Kapczinski F. Mental disorders in a community assisted by the Family Health Program. Cad Saude Publica 2008; 24(7):1641-1650.

16. Gonçalves AM, Sena RR. Psychiatric reform in Brazil: contextualization and consequences regarding the care for the mentally ill in their family environment. Rev Lat Am Enfermagem 2001; 9(2):48-55.

17. Tunde-Ayinmode MF. Psychosocial impact of sickle cell disease on mothers of affected children seen at University of Ilorin Teaching Hospital, Ilorin, Nigeria. East Afr Med J 2007; 84(9):410-419.

18. Bruns A, Hilário MO, Jennings F, Silva CA, Natour J. Quality of life and impact of the disease on primary caregivers of juvenile idiopathic arthritis patients. Joint Bone Spine 2008; 75(2):149-154.

19. Zendron DPF. Satisfaction of family caregivers of patients with mental disorders with a mental health service in na interior city [dissertation]. Ribeirão Preto: Escola de Enfermagem de Ribeirão Preto, Universidade de São Paulo; 2013.

20. Litzelman K, Skinner HG, Gangnon RE, Nieto FJ, Malecki K, Witt WP. Role of Global Stress in the Health-Related Quality of Life of Caregivers: Evidence from the Survey of the Health of Wisconsin. Qual Life Res 2014; 23(5):1569-1578.

21. Amendola F, Oliveira MAC, Alvarenga MRM. Quality of life of caregivers of dependent patients in the Family Health Program. Texto Contexto Enferm 2008; 17(2):266-272.

22. Amendola F, Oliveira MAC, Alvarenga MRM. Influence of social support on quality of life of caregivers of dependent individuals. Rev Esc Enferm USP 2011; 45(4):884-889.

23. Tabelão VP, Tomasi E, Quevedo LA. Burden on relatives of people with psychic disorder: levels and associated factors. Rev Psiq Clín 2014; 41(3):63-66.

Artigo apresentado em 10/11/2015

Aprovado em 04/05/2016

Versão final apresentada em 06/05/2016 
